\title{
Correspondence
}

\section{Inhibitory effect of sodium aurothiomalate on a chronic inflammatory model in the rat}

SIR, The effects of gold salts in adjuvant arthritis have for a long time been subject to discussion, ${ }^{1}$ and in a recent report ${ }^{2}$ the authors found that pretreatment of rats for three months with sodium aurothiomalate (NATM) exacerbated the severity of the subsequent adjuvant arthritis. Like other workers ${ }^{3}{ }^{4}$ we have found it possible to inhibit adjuvant arthritis in the rat with NATM, and the experiment described here may be of interest.

Male Wistar rats (OLAC) initially weighing 190-240 g received an injection into the right hind paw of $0.5 \mathrm{mg}$ dead Mycobacterium tuberculosis cells in $0.1 \mathrm{ml}$ mineral oil. NATM 13.5 or $3.4 \mathrm{mg} / \mathrm{kg}$ was administered by injection into the thigh muscle daily for 14 days, starting at the time of adjuvant injection, the site being alternated between left and right limbs to reduce the risk of necrosis. Controls received intramuscular saline, and another group of animals were given indomethacin $2 \mathrm{mg} / \mathrm{kg}$ orally. The disease was monitored regularly for 28 days by measurement with calipers of the injected paw depth and by a subjective scoring system after the onset of secondary arthritis. A count was made of the affected joints of all four limbs and the ears and tail, with a weighting being given for severity of inflammation such that the theoretical maximum score for each animal was 28 . The person performing the measurements was aware of the treatment of each group. Bodyweight changes were recorded throughout the experiment, and at termination the post-mortem thymus and spleen weights were measured.

The effects of NATM on the arthritis are summarised in Table 1 and show a dose-related inhibition of both the injected paw depth and the arthritis score. With NATM, unlike indomethacin, no antagonism was seen of the acute paw swelling at day 3 . At day 28 the animals which had received NATM $13.5 \mathrm{mg} / \mathrm{kg}$ showed an enhanced bodyweight gain over arthritic control animals, and both doses of NATM showed a reversal of disease-associated organ weight changes (Table 2).

Table 2 Post-mortem organ weights (day 28)

\begin{tabular}{|c|c|c|c|}
\hline Compound & $\begin{array}{l}\text { Dose } \\
(\mathrm{mg} / \mathrm{kg}) \\
\text { and } \\
\text { route }\end{array}$ & $\begin{array}{l}\text { Mean thymus wt } \\
(m g \pm S E)^{*}\end{array}$ & $\begin{array}{l}\text { Mean spleen wt } \\
(m g \pm S E)^{*}\end{array}$ \\
\hline Saline & $\overline{\mathrm{IM}} \|$ & $207 \cdot 8 \pm 27 \cdot 9$ & $1379 \cdot 4 \pm 91 \cdot 8$ \\
\hline NATM & $\begin{array}{l}13 \cdot 5 \\
\mathrm{IM}\end{array}$ & $320 \cdot 8 \pm 18 \cdot 0 \ddagger$ & $965 \cdot 9 \pm 25 \cdot 7 \S$ \\
\hline NATM & $\begin{array}{l}3 \cdot 4 \\
\mathrm{IM}\end{array}$ & $281 \cdot 1 \pm 21 \cdot 0$ & $1073 \cdot 0 \pm 53 \cdot 0 \dagger$ \\
\hline Indomethacin & $\begin{array}{c}2 \\
\text { p.o. } \|\end{array}$ & $327 \cdot 5 \pm 29 \cdot 0 \ddagger$ & $967 \cdot 5 \pm 87 \cdot 9 \ddagger$ \\
\hline
\end{tabular}

*Non-arthritic animals of same age and strain have thymus weight $400-450 \mathrm{mg}$, spleen weight $900-1000 \mathrm{mg}$.

$t \mathrm{p}<0.05$ Difference from control

$\ddagger \mathrm{p}<0.01\}$ group measured by

$\S \mathrm{p}<0.001$ Student's $t$ test.

|IIM=intramuscularly; p.o. $=$ orally .

Table 1 The effect of NATM on adjuvant-induced arthritis

\begin{tabular}{|c|c|c|c|c|c|c|c|c|c|}
\hline \multirow[t]{2}{*}{ Compound } & \multirow{2}{*}{$\begin{array}{l}\text { Dose } \\
\text { (mg/kg) } \\
\text { and } \\
\text { route }\end{array}$} & \multicolumn{3}{|c|}{$\begin{array}{l}\text { Mean right paw depth } \\
(m m \pm S E)^{*}\end{array}$} & \multicolumn{3}{|c|}{$\begin{array}{l}\text { Mean change in body weight } \\
\text { from day } 0(g \pm S E)\end{array}$} & \multicolumn{2}{|c|}{$\begin{array}{l}\text { Mean arthritis } \\
\text { score }\end{array}$} \\
\hline & & Day 3 & Day 14 & Day 28 & Day 3 & Day 14 & Day 28 & Day 14 & Day 28 \\
\hline \multirow[t]{2}{*}{ Saline } & - & $6 \cdot 5$ & $8 \cdot 6$ & $10 \cdot 5$ & $-0 \cdot 5$ & $-0 \cdot 1$ & $5 \cdot 6$ & \multirow[t]{2}{*}{$11 \cdot 8$} & \multirow[t]{2}{*}{$14 \cdot 3$} \\
\hline & IM $\|$ & $\pm 0 \cdot 2$ & \pm 0.4 & \pm 0.5 & \pm 1.9 & $\pm 4 \cdot 7$ & $\pm 4 \cdot 8$ & & \\
\hline \multirow[t]{2}{*}{ NATM } & $13 \cdot 5$ & $6 \cdot 7$ & $6.5 \S$ & $7 \cdot 6 \ddagger$ & -5.9 & $2 \cdot 5$ & $2.5 .3 t$ & \multirow[t]{2}{*}{$9 \cdot 3 \ddagger$} & \multirow[t]{2}{*}{$11 \cdot 5 \ddagger$} \\
\hline & IM & \pm 0.2 & \pm 0.2 & \pm 0.5 & $\pm 2 \cdot 5$ & \pm 3.8 & $\pm 7 \cdot 4$ & & \\
\hline \multirow[t]{2}{*}{ NATM } & $3 \cdot 4$ & 6.4 & $7 \cdot 2+$ & $8.9 t$ & -0.3 & $-3 \cdot 1$ & $8 \cdot 4$ & \multirow[t]{2}{*}{$11 \cdot 3$} & \multirow[t]{2}{*}{$12 \cdot 3+$} \\
\hline & IM & $\pm 0 \cdot 2$ & \pm 0.4 & \pm 0.4 & $\pm 1 \cdot 6$ & \pm 6.7 & $\pm 7 \cdot 2$ & & \\
\hline \multirow[t]{2}{*}{ Indomethacin } & 2 & $5 \cdot 3$ & $5 \cdot 8 \S$ & $7 \cdot 9 \S$ & $2 \cdot 9$ & $27 \cdot 0 \ddagger$ & $27 \cdot 9 \dagger$ & \multirow[t]{2}{*}{$6 \cdot 4 \S$} & \multirow[t]{2}{*}{$10 \cdot 6 \S$} \\
\hline & p.o.\| & $\pm 0 \cdot 1 \S$ & $\pm 0 \cdot 1$ & \pm 0.3 & $\pm 1 \cdot 6$ & \pm 4.9 & $\pm 6 \cdot 7$ & & \\
\hline
\end{tabular}

*Normal uninflamed paw $\simeq 4.5 \mathrm{~mm}$.

$t \mathrm{p}<0.05]$ Difference from control group measured by Student's $t$ test

$\ddagger \mathrm{p}<0.01$ for paw depth and bodyweight change and

$\S \mathrm{p}<0.001$ by Mann-Whitney $U$ test for arthritis score.

$\| \mathbf{I}=$ intramuscularly; p.o.=orally.

Compounds administered days $0-13$ inclusive.

Each group consisted of eight rats and there were no deaths. 
A recent review ${ }^{1}$ has suggested that reports of gold salts being inhibitory to adjuvant arthritis following parenteral administration may be explained by counterirritancy. While we cannot completely preclude this possibility, the following points seem relevant. The injection sites were examined daily and no signs of irritation or necrosis were observed, the animals were not distressed, and there were no adverse effects on bodyweight gain. NATM had no effect on the acute indomethacin-sensitive inflammation at day 3 , but the secondary arthritis was inhibited in a dosedependent manner, with the activity being maintained for 14 days after cessation of dosing. Finally, the systemic noninflammatory disease was modified, with NATM reversing the thymic regression and splenic hypertrophy seen in adjuvant arthritic rats.

These results are similar to those obtained by Walz $e t$ al. ${ }^{4}$ who in addition showed a correlation between antiarthritic activity and serum gold levels. It appears that under certain conditions adjuvant-induced arthritis in the rat can be used to evaluate the efficacy of gold salts.

Beecham Pharmaceuticals,

Medicinal Research Centre,

F R MANGAN

Coldharbour Road,

The Pinnacles,

Harlow,

Essex CM19 5AD

\section{References}

1 Billingham M E J. Models of arthritis and the search for antiarthritic drugs. Pharmacol Ther 1983; 21: 389-428.

2 Haskard D O, Currey H L F. Gold exacerbates adjuvant arthritis in the rat. Ann Rheum Dis 1984; 43: 350-1.

3 Sofia R D, Knoblock L C, Douglas J F. Effect of concurrent administration of aspirin, indomethacin or hydrocortisone with gold sodium thiomalate against adjuvant-induced arthritis in the rat. Agents Actions 1976; 6: 728-34.

4 Walz D T, Di Martino M J, Misher A. Suppression of adjuvantinduced arthritis in the rat by gold sodium thiomalate. Ann Rheum Dis 1971; 30: 303-6.

\section{Hypogammaglobulinaemia associated with gold therapy}

SIR, The recent report of two patients with hypogammaglobulinaemia associated with gold therapy ${ }^{1}$ prompts me to report the case of a man with seronegative rheumatoid arthritis who developed hypogammaglobulinaemia while on gold therapy. The development of hypogammaglobulinaemia coincided with a complete clinical remission. His immunoglobulin levels have returned to normal, and he has remained in remission for nearly five years.

The patient was well until 1976 when at age 46 he developed a symmetrical polyarthritis. The latex fixation test was negative. In April 1978 despite salicylate therapy and naproxen $250 \mathrm{mg}$ twice a day, he still had persistent
Table 1 Serum immunoglobulins

\begin{tabular}{|c|c|c|c|c|}
\hline \multirow[t]{2}{*}{ Date } & \multicolumn{3}{|l|}{ Serum } & \multirow{2}{*}{$\begin{array}{l}\text { Total dose } \\
\text { of gold } \\
\text { (mg) }\end{array}$} \\
\hline & $\lg G$ & $\lg A$ & $\lg M$ & \\
\hline 4 May 1978 & $20 \cdot 98$ & $2 \cdot 11$ & $1 \cdot 17$ & 60 \\
\hline 8 Aug 1978 & $12 \cdot 91$ & $1 \cdot 12$ & 0.61 & 735 \\
\hline $6 \mathrm{Dec} 1978$ & $6 \cdot 1$ & $0 \cdot 26$ & $0 \cdot 19$ & 1200 \\
\hline 4 Jan 1980 & $3 \cdot 52$ & $0 \cdot 20$ & $0 \cdot 10$ & 1540 \\
\hline 27 Feb 1980 & $4 \cdot 11$ & $0 \cdot 82$ & 0.32 & \\
\hline 19 Nov 1980 & $6 \cdot 91$ & 0.63 & 0.53 & \\
\hline 16 Oct 1984 & $8 \cdot 64$ & 1.98 & $1 \cdot 03$ & \\
\hline Normal (g/l) & $5 \cdot 6-15 \cdot 12$ & $1.04-4.48$ & $0 \cdot 66-3 \cdot 52$ & $\begin{array}{l}\text { (by nephel- } \\
\text { ometer) }\end{array}$ \\
\hline
\end{tabular}

active synovitis of the wrists, metacarpophalangeal joints, $\sim$ proximal interphalangeal joints, knees, and metatar- $\overrightarrow{-}$ sophalangeal (MTP) joints. The latex test was againo negative. Radiographs of the hands were normal, but the feet showed small erosions of the right third and left fifth $\vec{\overrightarrow{ }}$ MTP joints. The serum IgG level was raised, and serialo levels are shown in Table 1 . He was started on sodium aurothiomalate $50 \mathrm{mg}$ intramuscularly (IM) weekly, and by December 1978 he was markedly improved with only $\mathscr{C}_{0}$ synovitis of both wrists. However, serum levels of $\operatorname{IgA}$ ander IgM had fallen below normal levels. He was continued on gold $25 \mathrm{mg}$ IM monthly and was seen again in January 1980 ? when he was in complete remission. However, his serum IgG level had fallen below normal. Gold was discontinuedo as were the salicylates and naproxen, and his immuno- 0 globulin levels returned to normal. No infections occurred $\stackrel{\mathbb{Q}}{2}$ during the course of his illness. He remains in clinical $\overrightarrow{\vec{P}}$ remission, and radiographs of his hands and feet remain 3 unchanged.

It is interesting to speculate whether there is a relation ship between the development of hypogammaglobulin-aemia and the excellent response to gold seen in this patient.

Rheumatic Disease Unit,

Health Sciences Centre,

T HUNTER

800 Sherbrook Street,

Winnipeg,

Manitoba,

Canada R3A 1M4

\section{Reference}

1 So A K L, Peskett S A, Webster A D B. Hypogammaglobuli N naemia associated with gold therapy. Ann Rheum Dis 1984; 43. $581-2$.

\section{Non-steroidal anti-inflammatory drugs and adverse renal effects}

SIR, We read with interest the report by Sellars et al. of the induction of nephrotic syndrome and renal impairment 